\title{
Assessment of water quality in Hawkesbury-Nepean River in Sydney using water quality index and multivariate analysis
}

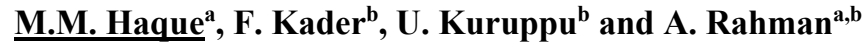 \\ ${ }^{a}$ Institute for Infrastructure Engineering, Western Sydney University \\ ${ }^{b}$ School of Computing, Engineering and Mathematics, University of Western Sydney \\ Email:m.haque@uws.edu.au
}

\begin{abstract}
This study has assessed the water quality status of the Hawkesbury-Nepean River (HNR) in Sydney, Australia. It is based on the collected data of 12 water quality parameters at four monitoring stations along the river. HNR is one of the most important rivers in Australia which supplies over 90\% of Sydney's potable water for more than 4.8 million people. Canadian Water Quality Index (CWQI) is adopted in this study to summarise the water quality status at the individual stations by categorising the water quality in five divisions; poor, marginal, fair, good and excellent. In addition, water quality parameters are regressed with the calculated CWQI to identify the significant parameters. Based on the calculated CWQI, only one station is found to fall in 'fair' category, two in 'marginal' and one in 'poor' water quality categories. No significant trend is observed in the CWQI for the stations during the period of data collection; however, one station shows slight trend of decreasing water quality. The preliminary results of the regression analysis demonstrate that not all the water quality parameters are significant in explaining the CWQI at the stations. The results of this study are expected to provide useful information for water quality management, and to form the basis for further investigation.
\end{abstract}

Keywords: $\quad$ Multiple linear regression, Hawkesbury-Nepean River, water quality index, Australia 


\section{INTRODUCTION}

Deterioration of river water quality has become a major issue in many countries around the globe as a consequence of increasing urbanisation and industrialisation. River water quality in a region is mainly affected by both the anthropogenic activities (e.g. agricultural and industrial activities) and natural processes (e.g. changes in rainfall, increase in droughts and floods, and bank erosion) (Simeonov et al., 2003). Rivers among the water bodies are considered to be the most vulnerable to pollution due to their role in receiving the wastewater from municipalities and industries, and runoff from agricultural land. Since, rivers are primary sources of water for drinking, irrigation and industrial purposes for many localities around the globe, it is vital to prevent and control the pollution of river water. Maintaining good quality river water is also important for the community important in the context of climate change conditions as available water resources are likely to be reduced (Haque et al., 2015) and urban water demand is like to be increased due to climate change in future (Haque et al., 2014). In order to achieve this, reliable information on water quality is needed, which can be obtained by establishing regular water quality monitoring programs. Water quality monitoring programs generally produce large and complex data matrix consisting of a numbers of water quality parameters, which are often difficult to interpret and assess overall water quality.

Water quality index (WQI) is an effective tool to obtain comprehensive information on water quality in an easily understandable format that can be used by the managers, decision makers and public (ŠtambukGiljanović, 1999; Bordalo et al., 2001). It transforms a large quantity of water quality data into a single number. The first study on WQI was done by Horton (1965); since then, several WQIs have been developed based on different types and numbers of water quality parameters. The concept of WQI is based on the principle of comparing water quality parameters with respective regulatory standards. It severs the main purpose of describing the overall water quality status and water quality trends. It provides information on a scale from 0 to 100, where higher WQI indicates better water quality of water and lower values shows poor water quality. River water can be classified based on the identified single value of WQI for the purposes of various uses.

In this study, water quality status of the four water quality monitoring stations along the HawkesburyNepean River (HNR) in Sydney, Australia is assessed by calculating WQI for the individual stations. HNR is one of the most important rivers in Australia as it supplies water to over 4.8 million people in Sydney. This study classifies the conditions of river water quality of the four stations based on the calculated WQI and identifies the trend in WQI. It also attempts to find the significant water quality parameters at the individual stations in explaining WQI. The preliminary results of this study are expected to provide useful information for water quality management and to form the basis for further investigation.

\section{STUDY AREA AND DATA}

This study is based on the HNR, which supplies over $90 \%$ of Sydney's potable water. Therefore, monitoring and assessing the water quality status of this river is of greater importance. This river is also used for a variety of agricultural, industrial, recreational and tourist activities (Kuruppu and Rahman, 2015). It is a combination of two major rivers, the Hawkesbury River $(145 \mathrm{~km})$ and the Nepean River $(155 \mathrm{~km})$ (Markich and Brown, 1998). In this study, a total of 12 water quality parameters obtained from four sampling stations (Table 1) during the period of 2002 to 2013 along the HNR are investigated to identify the changes at different stations over time, and for comparison of water quality among the stations. The selected water quality parameters and the standard values of those parameters adopted by the Australian and New Zealand Guidelines for Fresh and Marine Water Quality (ANZECC) are presented in Table 2.

Table 1. Water quality monitoring stations adopted in this study along the Hawkesbury-Nepean River.

\begin{tabular}{|c|c|c|c|}
\hline Station ID & Site & Longitudes & Latitudes \\
\hline N14 & $\begin{array}{c}\text { Hawkesbury River at Wisemans Ferry } \\
\text { downstream of Car Ferry }\end{array}$ & 150.98 & -33.38 \\
\hline N21 & $\begin{array}{c}\text { Hawkesbury River at Lower Portland } \\
\text { upstream of Colo River }\end{array}$ & 150.88 & -33.43 \\
\hline N35 & $\begin{array}{c}\text { Hawkesbury River at Wilberforce upstream } \\
\text { of Cattai Creek }\end{array}$ & 150.83 & -33.58 \\
\hline
\end{tabular}


Haque et al., Assessment of water quality in Hawkesbury-Nepean River in Sydney

\begin{tabular}{|l|c|c|c|} 
N42 & $\begin{array}{c}\text { Hawkesbury River at North Richmond } \\
\text { upstream of North Richmond Water } \\
\text { Treatment Works }\end{array}$ & 150.71 & -33.59 \\
\hline
\end{tabular}

Table 2. Water quality parameters adopted in this study and standard values of the parameters recommended by the ANZECC guidelines.

\begin{tabular}{|c|c|c|}
\hline Water quality parameter & Unit & ANZECC trigger value \\
\hline $\mathrm{pH}$ & & $6<\mathrm{pH}<8$ \\
\hline Iron Total & $\mathrm{mg} / \mathrm{L}$ & $<0.3$ \\
\hline Chlorophyll-a & $\mathrm{ug} / \mathrm{L}$ & $<5$ \\
\hline True Colour & & $<15$ \\
\hline Nitrogen Total & $\mathrm{mg} / \mathrm{L}$ & $<0.35$ \\
\hline Turbidity & $\mathrm{NTU}$ & $<20$ \\
\hline Alkalinity & $\mathrm{mgCaCO} / \mathrm{L}$ & $<0.2$ \\
\hline Aluminum Total & $\mathrm{mg} / \mathrm{L}$ & $>5$ \\
\hline Dissolved Oxygen & $\mathrm{mg} / \mathrm{L}$ & $<0.05$ \\
\hline Phosphorus Total & $\mathrm{mg} / \mathrm{L}$ & $<20$ \\
\hline Suspended Solids & $\mathrm{mg} / \mathrm{L}$ & $<0.35$ \\
\hline Conductivity Field & $\mathrm{mS} / \mathrm{cm}$ & \\
\hline
\end{tabular}

\section{METHODS}

The WQI methods that are commonly adopted to represent water quality status are (Said et al., 2004): US National Sanitation Foundation Water Quality Index (NSFWQI), Canadian Water Quality index (CWQI), British Columbia Water Quality Index (BCWQI), Oregon Water Quality Index (OWQI) and Florida Stream Water Quality Index (FWQI). In this study, CWQI (CCME, 2001) is adopted to derive an overall and easily understood description of water quality status at the four stations of the HNR. CWQI was developed by Canadian Council of Ministry of Environment in 2001. Three conditions are generally checked in calculating CWQI: (i) number of water quality parameters that do not meet the recommended standards, generally termed as Scope $\left(F_{1}\right)$, (ii) number of times when the these standards are not meet, termed as Frequency $\left(F_{2}\right)$ and (iii) the amount of deviation of the water quality parameters from the standard values, termed as Amplitude $\left(\mathrm{F}_{3}\right)$.

The CWQI is calculated using these above three conditions by Equation 1:

$\mathrm{CWQI}=100-\left(\frac{\sqrt{\mathrm{F}_{1}{ }^{2}+\mathrm{F}_{2}{ }^{2}+\mathrm{F}_{3}{ }^{2}}}{1.732}\right)$

The index produces a number between 0 (worst water quality) and 100 (best water quality). These numbers are divided into 5 descriptive categories to represent water quality conditions, which are as follows:

1. When WQI ranges from 0 to 44 , it represents 'Poor' water quality, indicating water quality almost always deviates from the standard levels,

2. When WQI ranges from 45 to 64 , it represents 'Marginal' water quality, indicating water quality frequently deviates from the standard levels,

3. When WQI ranges from 65 to 79 , it represents 'Fair' water quality, indicating water quality is usually protected, but occasionally deviates from the standard levels,

4. When WQI ranges from 80 to 94 , it represents 'Good' water quality, indicating water quality is protected but deviate from the standard level in rare occasions, and

5. When WQI ranges from 95 to 100 , it represents 'Excellent' water quality, indicating the conditions close to natural or pristine levels.

After calculating WQI, the stepwise regression analysis is undertaken with the water quality parameters as independent variables and the WQI as dependent variable to identity the statistically significant parameters at each of the monitoring stations. 


\section{RESULTS}

Average WQIs for the period of 2002 to 2013 of the four water sample collection stations along the HNR are presented in Figure 1. The values below the straight line represent the status of the water sample conditions. For example, if the WQI values of any station fall below the red line then the water quality of that station can be considered as "poor". As can be seen in Figure 1 that water quality of the three stations, N14, N21 and N35 is in "marginal" category indicating that water quality conditions are frequently compromised at these stations and are often deviated from the desirable levels. Only the station, N42 shows a relatively better water condition than the other three stations as water quality at this station fall under "fair" category. It should be noted here that none of the station shows either "good" or "excellent" water quality conditions.

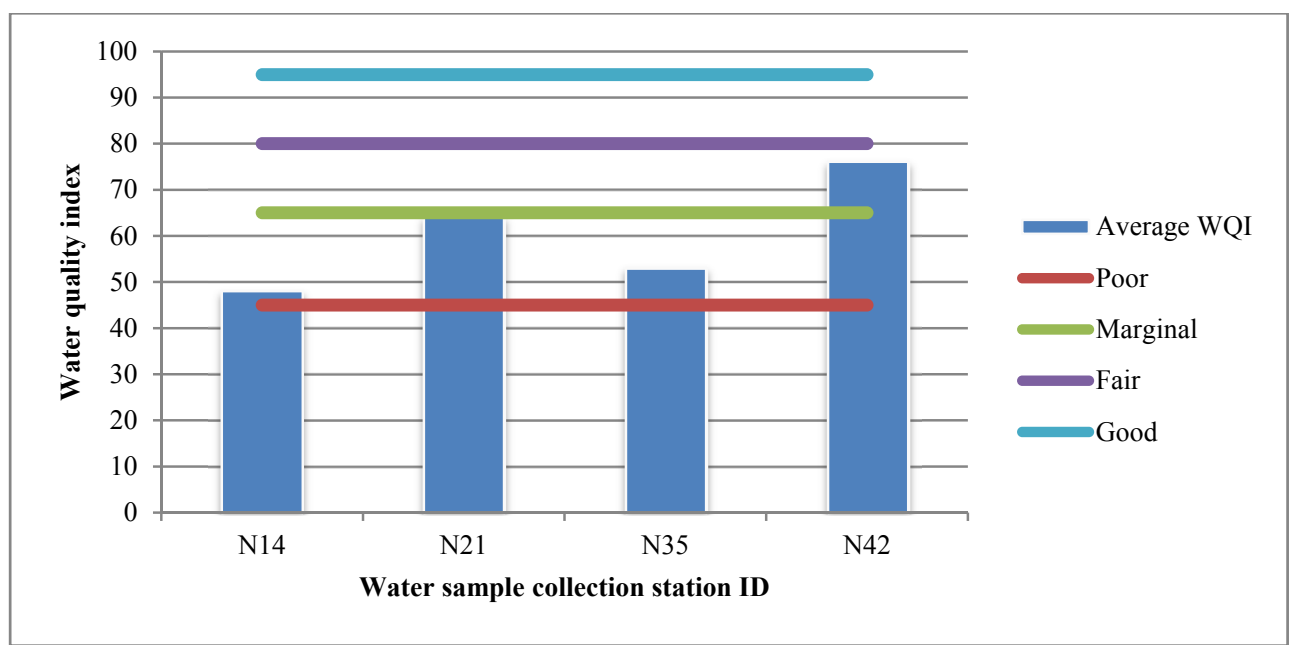

Figure 1. Average water quality index of the four stations along the HNR during the period of 2002 to 2013.

WQI values at the individual stations during the period of 2002 to 2013 are presented in Figures 2(a) to 2(d). At N14, WQI values are found to be varied in the range of 25 to 78 indicating a notable variation in the water quality conditions. In 2007, the water quality condition is found to be "poor" as the WQI value is very low as shown in Figure 2(a). Interestingly, at the beginning of year 2006, the water quality conditions are found to be the highest during the period of 2002 to 2013. But for some reasons, the water quality conditions have deteriorated drastically in 2007 . There may be several contributing factors to low WQI in 2007, such as errors in data collection or high pollution occurred during that year. However, such kind of large variations have also been found in the period of 2009 to 2012, which need to be investigated further to get in depth knowledge about the water quality conditions. Nevertheless, the trend in water quality index shows an increasing trend indicating that water quality conditions are getting better at N14 over the time.

As can be seen in Figure 2(b), the variation in the WQI at N21 is in the range of 38 to 83, which is also high. High WQI to low WQI variations are found in several years, e.g. 2004 to 2005, 2009 to 2010 and 2011 to 2012, which warrant further investigation for such large drop in water quality conditions. The trend is found to be mild, and the coefficient of determination $\left(R^{2}\right)$ value is found to be very low indicating that average water quality conditions remains the same during the period of 2002 to 2013.

At N35, variations in the WQI values are also found to be notably high as these vary in the range of 22 to 79 as shown in Figure 2(c). Variations from high WQI to low WQI are found in the periods 2003-2004 and 2011-2012. Water quality conditions are found to be "poor" for several years. The trend at N35 does not show any notable pattern and $R^{2}$ value is very low indicating the same conditions as N21. At N42, the high to low WQI variations are not found to be that significant as compared to other stations (Figure 2(d)). The water quality conditions at N42 are found to be relatively better than the other three stations as the WQI values range from 53 to 100 . However, the trend line shows a decreasing pattern in WQI values indicating that water quality conditions have been gradually degrading at N42 though $R^{2}$ value of the trend line is not high. 

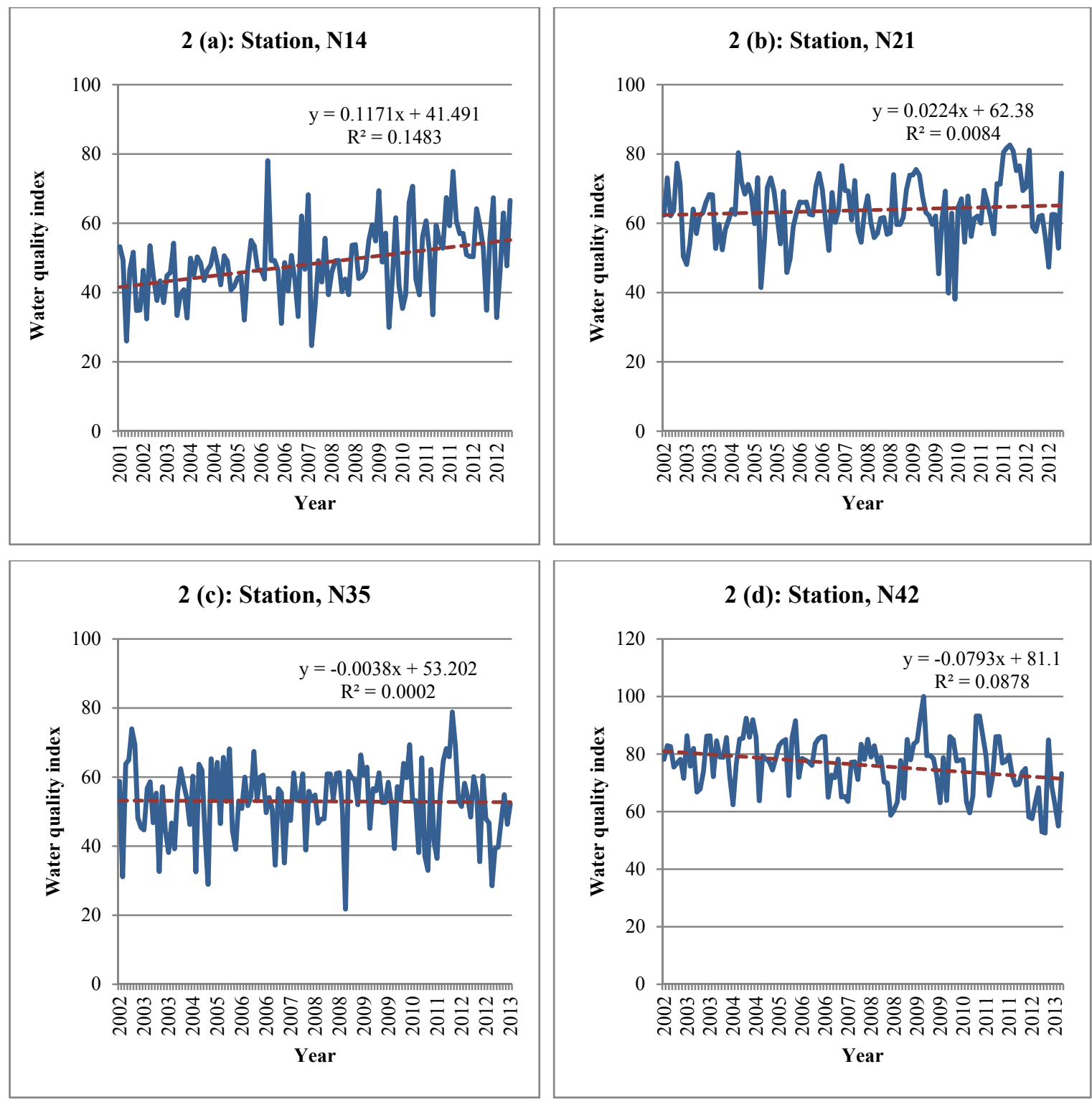

Figure 2(a-d). Water quality index (WQI) values at the four stations (N14, N21, N35 and N42) along the HNR during the period of 2002 to 2013.

The regression results of the water quality parameters with the WQI are presented in Table 3. The parameters that are statistically significant at 5\% significance level are retained in the stepwise regression analysis. The results show that $4,10,8$ and 7 numbers of water quality parameters are significant for the N14, N21, N35 and N42 stations, respectively out of the 12 water quality parameters. The $R^{2}$ values are found to be satisfactory for all the stations, and the standard error of estimates values are found to be in the good range. The results indicate that these parameters are able to explain and model the water quality conditions in a satisfactory manner. However, further investigations are needed by applying multivariate analysis such as principal component analysis, and by examining the land use types and possible sources of contamination/pollution for the individual stations. 
Table 3. Statistically significant water quality parameters at the stations.

\begin{tabular}{|c|c|c|c|}
\hline Station ID & Dependent variables & $R^{2}$ & Standard error of estimate \\
\hline N14 & $\begin{array}{l}\text { (i) Iron total, (ii) Aluminium total, (iii) Suspended } \\
\text { solids, (iv)Conductivity fields }\end{array}$ & $63.50 \%$ & 6.34 \\
\hline $\mathrm{N} 21$ & $\begin{array}{l}\text { (i) } \mathrm{pH} \text {, (ii) Iron total, (iii) Chlorophyll-a, (iv) TRUE } \\
\text { color, (v) Nitrogen total, (vi) Alkalinity, (vii) } \\
\text { Dissolved oxygen, (viii) Phosphorus total, (ix) } \\
\text { Suspended solids, (x) Conductivity fields }\end{array}$ & $75.47 \%$ & 4.54 \\
\hline N35 & $\begin{array}{l}\text { (i) Iron total, (ii) Chlorophyll-a, (iii) TRUE color,(iv) } \\
\text { Alkalinity (v) Aluminium total, (vi) Phosphorus } \\
\text { total, (vii) Suspended solids, (viii) Conductivity } \\
\text { fields }\end{array}$ & $72.90 \%$ & 5.58 \\
\hline N42 & $\begin{array}{c}\text { (i) } \mathrm{pH} \text {, (ii) Iron total, (iii) Chlorophyll-a, (iv) TRUE } \\
\text { color, (v) Nitrogen total, (vi) Alkalinity, (vii) } \\
\text { Suspended solids }\end{array}$ & $75.50 \%$ & 4.82 \\
\hline
\end{tabular}

\section{CONCLUSION}

In this study, water quality state at 4 water quality monitoring stations along the Hawkesbury-Nepean River (HNR) is assessed. It is found that none of the stations shows 'excellent' or 'good' water quality condition. Only one station shows 'fair' water quality condition, two of them show 'marginal' and one shows 'poor' water quality. Trend in water quality index (WQI) at the individual stations demonstrate a large variation (high to low) in WQI in the last few years indicating that the water quality in the HNR has not been stable in recent years. No significant trend has been found in the WQI values for the stations; however one station (N42) shows gradual decrease in WQI values over time. Results of the regression analysis show that not all the 12 water quality parameters are significant in explaining WQI. The preliminary results demonstrate that $4,10,8$ and 7 water quality parameters (out of twelve) are significant in the regression analysis for stations N14, N21, N35 and N42, respectively. Further investigation is needed to understand the overall water quality in the HNR.

\section{ACKNOWLEDGEMENTS}

The authors acknowledge WaterNSW for providing water quality data for this study. The comments and findings presented in this paper are of authors only and do not reflect the opinion of WaterNSW, and any other organisation.

\section{REFERENCES}

Bordalo, A.A., Nilsumranchit, W., and Chalermwat, K. (2001). Water quality and uses of the Bangpakong River (Eastern Thailand). Water Research, 35(15), 3635-3642.

Boyacioglu, H. (2010). Utilization of the water quality index method as a classification tool. Environmental Monitoring and Assessment, 167(1-4), 115-124.

Canadian Council of Ministers of the Environment (CCME) (2001). Canadian water quality guidelines for the protection of aquatic life: CCME Water Quality Index 1.0. 
Haque, M.M., Rahman, A., Hagare, D., and Kibria, G. (2014). Probabilistic water demand forecasting using projected climatic data for Blue Mountains Water Supply System in Australia. Water Resources Management, 28(7), 1959-1971.

Haque, M.M., Rahman, A., Hagare, D., Kibria, G., and Karim, F. (2015) Estimation of catchment yield and associated uncertainties due to climate change in a mountainous catchment in Australia. Hydrological Processes, published online, DOI: 10.1002/hyp.10492.

Horton, R. K. (1965). An index-number system for rating water quality. Journal of Water Pollution Control Federation, 37(3), 300-306.

Kuruppu, U., and Rahman, A. (2015). Trends in water quality data in the Hawkesbury-Nepean River System, Australia. Journal of Water and Climate Change, doi:10.2166/wcc.2015.120.

Markich, S. J., and Brown, P. L. (1998). Relative importance of natural and anthropogenic influences on the fresh surface water chemistry of the Hawkesbury-Nepean River, south-eastern Australia. Science of the Total Environment, 217 (3), 201-230.

Said, A., Stevens, D. K., and Sehlke, G. (2004). An innovative index for evaluating water quality in streams. Environmental Assessment, 34(3), 406-414.

Simeonov, V., Stratis, J.A., Samara, C., Zachariadis, G., Voutsa, D., Anthemidis, A., Sofonioub, M., and Kouimtzisc, Th. (2003). Assessment of the surface water quality in Northern Greece. Water Research, 37(17), 4119-4124.

Štambuk-Giljanović, N. (1999). Water quality evaluation by index in Dalmatia. Water Research, 33(16), 3423-3440. 